\title{
UNCERTAINTY PRINCIPLE INEQUALITIES RELATED TO LAGUERRE-BESSEL TRANSFORM
}

\author{
SOUMEYA HAMEM AND LOTFI KAMOUN
}

Abstract. In this paper, an analogous of Heisenberg inequality is established for Laguerre-Bessel transform. Also, a local uncertainty principle for this transform is investigated.

Mathematics subject classification (2010): 42B10, 44A05, 44A35, 35K08.

Keywords and phrases: Heisenberg inequality, Laguerre-Bessel transform, heat kernel, local uncertainty principle.

\section{REFERENCES}

[1] P. C. BowIE, Uncertainty inequalities for Hankel transforms, SIAM J. Math. Anal 2 (1971), 601-606.

[2] E. Jebbari, M. Sifi And F. Soltani, Laguerre-Bessel wavelet transform, Glob. J. Pure Appl. Math. 1 (2005), 13-26.

[3] W. HEISENBERG, Über den anschaulichen inhalt der quantentheoretischen kinematik und machanik, Z. Phys. 43 (1927), 172-198.

[4] A. HUlanicki, Subalgebra of $L^{1}(G)$ associated with Laplacian on a Lie group, Colloq. Math. 31 (1974), 259-287.

[5] Z. Li AND L. LiU, Uncertainty principles for Jacobi expansions, J. Math. Anal. Appl. 286 (2003), $652-663$.

[6] Z. Li AND L. LiU, Uncertainty principles for Sturm-Liouville operators, Constr. Approx. 21 (2005), 193-205.

[7] R. MA, Heisenberg inequalities for Jacobi transforms, J. Math. Anal. Appl. 332 (2007), 155-163.

[8] R. MA, Heisenberg uncertainty principle on Chébli-Trimèche hypergroups, Pacific J. Math. 235 (2008), 289-296.

[9] S. OMRI AND L. T. RACHDI, Heisenberg-Pauli-Weyl uncertainty principle for the Riemann-Liouville operator, J. Inequal. Pure Appl. Math. 9, 3 (2008), 1-23.

[10] J. F. PRICE, Inequalities and local uncertainty principles, J. Math. Phys 24 (1983), 1711-1714.

[11] J. F. PRICE, Sharp local uncertainty principles, Studia Math. 85 (1987), 37-45.

[12] M. RöSLER, An uncertainty principle for the Dunkl transform, Bull. Austral. Math. Soc. 59 (1999), 353-360.

[13] M. Rösler And M. Voit, An uncertainty principle for Hankel transforms, Proc. Amer. Math. Soc. 127 (1999), 183-194.

[14] N. Shimeno, A note on the uncertainty principle for the Dunkl transform, J. Math. Sci. Univ. Tokyo 8 (2001), 33-42.

[15] E. M. SteIn, Singular integrals and differentiability properties of functions, Princeton University Press Princeton, New Jersey, 1970.

[16] H. WeYL, Gruppentheorie und Quantenmechanik, S. Hirzel, Leipzig, 1928. Revised English edition: The Theory of Groups and Quantum Mechanics, Methuen, London, 1931; reprinted by Dover, New York, 1950. 